\title{
Effect of Lithium on Smooth Muscle Contraction and Phosphorylation of Myosin Light Chain by MLCK
}

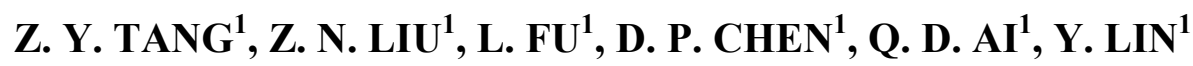 \\ ${ }^{1}$ Department of Pharmacology, Dalian Medical University, Dalian, China
}

Received February 12, 2010

Accepted April 16, 2010

On-line June 9, 2010

\begin{abstract}
Summary
The aims of our study were to investigate into the effect of lithium on smooth muscle contraction and phosphorylation of myosin light chain $\left(M_{2} C_{20}\right.$ ) by MLCK and to find out the clue of its mechanism. Isolated rabbit duodenum smooth muscle strips were used to study the effects of lithium on their contractile activity under the condition of Krebs' solution by means of HW$400 \mathrm{~S}$ constant temperature smooth muscle trough. Myosin and MLCK were purified from the chicken gizzard smooth muscle. Myosin phosphorylation was determined by Glycerol-PAGE, myosin $\mathrm{Mg}^{2+}$-ATPase activity was measured by Pi liberation method. Lithium (10-40 $\mathrm{mM}$ ) inhibited the contraction in duodenum in a dose-related and time-dependent manner. Lithium could also inhibit the extent of myosin phosphorylation in a dose-related and time-dependent manner, whereas it inhibited $\mathrm{Mg}^{2+}$-ATPase activity in a dose-related manner. Lithium inhibited smooth muscle contraction by inhibition of myosin phosphorylation and $\mathrm{Mg}^{2+}$-ATPase activity.
\end{abstract}

\section{Key words}

Lithium • Smooth muscle contraction • Phosphorylation of myosin light chain $\left(\mathrm{MLC}_{20}\right) \bullet$ Myosin $\mathrm{Mg}^{2+}$-ATPase

\section{Corresponding author}

Y. Lin, Department of Pharmacology, Dalian Medical University, West Section 9, South Road of Lvshun, Dalian, P.R. China, 116044. E-mail: tangzeyao@yahoo.com.cn, dmu@mail.dlptt.In.cn

\section{Introduction}

The pharmacological actions of lithium are widespread. It can be a useful medication in the treatment of aggressive behavior and affective instability. It is not only able to reverse neurological damage induced by Vinca alkaloids, to act on myoneural preparations of rats (Abdel-Zaher 2000) and to improve the behavioral disorder in rats subjected to transient global cerebral ischemia, but it can also regulate hippocampal neurogenesis by ERK pathway and facilitate recovery of spatial learning and memory in rats after transient global cerebral ischemia (Yan et al. 2007). Thus it can effects various neuroprotective effects.

In higher concentrations $(10 \mathrm{mM})$ lithium inhibits in vitro functions of human polymorphonuclear leukocytes (PMNL) and lymphocytes (Anderson et al. 1982). On the other hand, it is related to diabetic disease (Hu et al. 1999) and its gastrointestinal complications is the most common one (Ozturk et al. 1992). Thus, its mechanism is perhaps related to glycogenic pathway (Kashour et al. 2003).

Moreover, lithium has many toxic or side effects. It has significant potential for neurotoxicity in normal population (Gill et al. 2003) and hyperthyroidism (Sadoul et al. 1994). It also disturbs the water-electrolyte equilibrium and affects the level of essential elements (Kielczykowska et al. 2003). A significant number of babies, which were exposed to lithium during gestation, suffered from developmental neuron deficits and depressed neurological status (Kozma 2005).

Therefore, it is widespread and highly effective drug in clinical practice (Ide et al. 2009). However, there are also many side effects (Diekmann 2000), particularly gastrointestinal ones including nausea, vomiting, diarrhea, anorexia, abdominal pain and dry mouth.

Though it was reported that lithium could act on endothelial-dependent relaxation in isolated rat aorta and on angiotensin II-stimulated vascular contraction 
(Dehpour et al. 1995), but the meachanism of its action is still not fully understood.

We are interested in the effects of lithium on muscle contractile function, because early symptoms of toxic cases have a relationship to gastrointestinal complications (Ozturk et al. 1992, Diekmann 2000). By investigating this mechanism we hope to find the way how to reduce these side effects of lithium.

Some believe that lithium exerts its pharmacological action by inhibiting the release of $\mathrm{N}$-acetyl- $\beta$ glucosaminidase induced by neomycin in the rat heart (Dehpour et al. 1995), by inhibiting substance P- and vasoactive intestinal peptide-induced relaxations on isolated porcine ophthalmic artery (Vincent 1992) or by influencing membrane adenosine triphosphatases in certain postural muscles of rats (Adipudi and Reddy 1994).

Therefore, we propose to study whether lithium can influence the smooth muscle contraction in isolated duodenum and the phosphorylation of myosin light chain $\left(\mathrm{MLC}_{20}\right)$ by MLCK level at the same time. The phosphorylation of $\mathrm{MLC}_{20}$ by $\mathrm{MLCK}$ is generally considered as the main primary mechanism for the regulation of the smooth muscle contraction. Phosphorylation can be simply described as an interaction of $\mathrm{Ca}^{2+}$ with $\mathrm{CaM}$ that induces a conformational change and activation of MLCK. The activated MLCK catalyzes phosphorylation of $\mathrm{MLC}_{20}$. The phosphorylation of $\mathrm{MLC}_{20}$ triggers cycling of myosin cross-bridges along actin filaments and the development of force (Tang et al. 2005).

\section{Methods and Materials}

\section{Animals}

The experiments were performed according to the rules of animal care and were approved by the Animal Protection Committee of Dalian Medical University. Rabbits (New Zealand, 1.5-2 kg) were used in all experiments. Animals were housed five per cage in a temperature-controlled room with a 12-h light-dark cycle (lights on at 7:00 a.m.). Food and water were available $a d$ libitum.

\section{Chemicals and instruments}

Lithium carbonate was purchased from SigmaAldrich (grade SigmaUltra; CAS Number: 554-13-2), Krebs solution contained (in $\mathrm{mM}$ ) sodium chloride 114.0, potassium chloride 4.7 , magnesium chloride 1.2 , calcium chloride 2.5, sodium dehydrogenate phosphate 1.8, glucose 11.5, sodium bicarbonate 18.0, $\mathrm{pH} 7.4 \pm 0.5$.

HW-400S constant temperature smooth muscle trough and BL-420F biology function experiment system were from Chengdu Tai Meng Science and Technology Ltd Co.

Perfusion of isolated duodenal segments and gastrointestinal motility

The abdomen was opened under urethane anesthesia. The duodenum between the pylorus and the Treitz ligament was removed and luminally perfused ex vivo as described earlier (Schümann and Hunder 1996). Briefly, the perfusion conditions were as follows: recirculation luminal perfusion with $30 \mathrm{ml}$ of bicarbonate-buffered Tyrode solution $\left(37{ }^{\circ} \mathrm{C}, \mathrm{pH} 7.2\right)$, which was equilibrated with $95 \% \mathrm{O}_{2}, 5 \% \mathrm{CO}_{2}, 25 \mathrm{~cm}$ $\mathrm{H}_{2} \mathrm{O}$ hydrostatic pressure, and $50 \mathrm{ml} / \mathrm{min}$ flow rate. The segments were kept in a moist chamber.

Contractions of the proximal duodenum were directly monitored by both frequency (contractions per minute) and amplitude (increase in pressure). In some cases, a motility index (frequency times mean amplitude) was calculated. Occasional movement artifacts were easily identified as spikes that appeared simultaneously in both recorded channels, and they were eliminated from data analysis. To determine the time at which tolerance developed to the motility effects of lithium, we compared the frequency of contractions in control recordings with the frequency of contractions after lithium infusion in different groups of animals, each animal served as its own control, and recording of intestinal motility was limited to $6 \mathrm{~h}$.

\section{Drug administration}

Lithium carbonate was administered according to previous articles (Anderson et al. 1982, Ravichandran et al. 1998, Erdal et al. 2005). Its pH was adjusted to 7.4 before it was used. It was injected into experimental chamber with mini-syringe. The dose for continuous administration of lithium was chosen to establish a steady-state concentration of lithium in the isolated intestine approximately equal to the $\mathrm{D}_{50}$, the effective dose of lithium that results in $50 \%$ increasing of transit.

Continuous administration of lithium $(5,10,20$, $40 \mathrm{mM}$, respectively) decreased the frequency and amplitude of contractions in the duodenum. To determine the time at which a tolerance developed to the motility effects of lithium, we compared the frequency and amplitude of contractions in control recordings with the 
frequency and amplitude of contractions at various times after the initiation of lithium infusion. Lithium infusion resulted in a significant decrease of contractility in the duodenum within $1 \mathrm{~h}$ and its effects persisted for 12-15 h. Tolerance of the contractile activity of the intestine to continuous administration of lithium was assessed either by measuring the time required for the duodenum to return to normal frequency of contractions or by recording the loss of effectiveness of lithium administration, which suggested that the intestinal contractile activity was tolerant to the effects of continuous lithium administration $(5,10,20,40 \mathrm{mM}$, respectively).

\section{Protein purification}

The myosin and MLCK used in our study were purified from the chicken gizzard smooth muscle to homogeneity as we described previously (Tang et al. 2005). The purity analysis of protein samples was assessed by SDS-PAGE.

\section{$M L C_{20}$ phosphorylation}

$\mathrm{MLC}_{20}$ phosphorylation was carried out in $20 \mathrm{mM}$ Tris- $\mathrm{HCl}$ ( $\mathrm{pH}$ 7.4) buffer containing $1 \mathrm{mM}$ dithiothreitol (DTT), $5 \mathrm{mM} \mathrm{MgCl}$, $60 \mathrm{mM} \mathrm{KCl,} 2 \mathrm{mM}$ ethylene glycol bis ( $\beta$-aminoethyl ether) N,N'-tetraacetic acid (EGTA), $4 \mu \mathrm{M}$ myosin and $2 \mathrm{mM}$ ATP. Various concentrations of MLCK, in different incubation time and incubation temperature for $\mathrm{MLC}_{20}$ phosphorylation are described in detail in the corresponding figure legends.

\section{Determination of $M L C_{20}$ phosphorylation}

Glycerol-polyacrylamide gel electrophoresis (Glycerol-PAGE) was used to measure the extent of $\mathrm{MLC}_{20}$ phosphorylation. Glycerol-PAGE was made using the separating gel containing $13.96 \%$ acrylamide, $0.372 \%$ bis-acrylamide, $40 \% \quad(\mathrm{v} / \mathrm{v})$ glycerol, and $0.375 \mathrm{M}$ Tris( $\mathrm{pH} 8.7)$; and the stacking gel containing $5.72 \%$ acrylamide, $0.152 \%$ bisacrylamide, $10 \%(\mathrm{v} / \mathrm{v})$ glycerol and $0.125 \mathrm{M}$ Tris-HC1 (pH 6.7). Myosin samples which contained $7.5 \mathrm{M}$ urea were added to the sample buffer containing $6 \mathrm{M}$ urea, $20 \%$ glycerol, $0.05 \mathrm{M}$ Tris ( $\mathrm{pH} 6.7$ ), $14 \mathrm{mM} \beta-\mathrm{ME}$, and a moderate amount of $0.01 \%$ Bromophenol Blue (BPB). The reaction mixture was loaded onto the gel.

The densitometry extent of $\mathrm{MLC}_{20}$ phosphorylation was measured by Scion Image software (Scion Co. Ltd). The extent of diphosphorylation (DIP) of $\mathrm{MLC}_{20}$ was selected as the control (calculated as $100 \%$ ); the extent of monophosphorylation (MIP) of $\mathrm{MLC}_{20}$ was a relative value calculated from MIP/DIP.

\section{Myosin $\mathrm{Mg}^{2+}$-ATPase activity measurement}

The method for measuring $\mathrm{Mg}^{2+}$-ATPase activity of myosin was described previously (Lin 2000).

\section{Other procedures}

Protein concentrations were determined by the method of Bradford (1976).The graphs of phosphorylation of $\mathrm{MLC}_{20}$ and myosin $\mathrm{Mg}^{2+}$-ATPase activities were obtained with Microsoft Excel 2005.

\section{Statistical analysis}

The results are expressed as means \pm S.D. Statistical analysis was performed with unpaired t test in the organ chamber experiment, and with one-way ANOVA in the other experiments. $\mathrm{P}<0.05$ was considered to indicate a statistical difference.

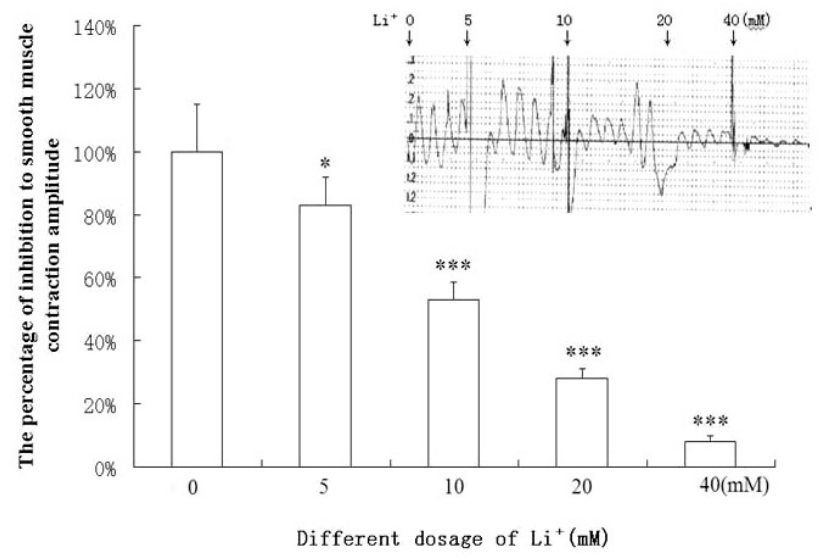

Fig. 1. Effect of lithium on the amplitude of smooth muscle contraction in different lithium concentrations. The inset represents the diagram of scope and frequency curves of smooth muscle contraction. The arrows show that the contraction scope and frequency were changed at different lithium concentrations. Asterisks indicate significant differences between particular lithium concentration groups ( $* * * \mathrm{P}<0.001, * \mathrm{P}<0.05)$. Data are means \pm S.D. $(n=8)$.

\section{Results}

Effect of different lithium concentration on the amplitude of smooth muscle myosin contraction

The dose-response curve for lithium-induced decrease of rabbit small duodenum contraction is shown in Figure 1. The $\mathrm{D}_{50}$ was calculated from the linear portion of the dose-response curve $(20-80 \%$ of maximum), using a linear regression analysis. The administration of lithium $(5,10,20,40 \mathrm{mM}$, respectively) 
resulted in an inhibition of contraction amplitude in duodenum (from $100 \pm 11.2 \%$ to $85 \pm 0.89 \%, 51 \pm 0.54 \%$, $25 \pm 0.31 \%$, and $5.0 \pm 0.52 \%$ ) (Fig. 1) in a dose-dependent manner. There was a significant difference between the amplitude of group (5 $\mathrm{mM})$ and the corresponding negative control $(\mathrm{P}<0.05)$. This difference became more significant at higher lithium concentrations $(\mathrm{P}<0.001)$.

Effect of lithium on the amplitude of smooth muscle myosin contraction at different incubation times

The administration of lithium (10 $\mathrm{mM})$ for 4,8 , 12, 16 and $20 \mathrm{~min}$, respectively, resulted in an inhibition of the amplitude of duodenum contractions (from $100 \pm 10.2 \%$ to $85 \pm 0.86 \%, 64 \pm 0.59 \%, 43 \pm 0.51 \%$, $24 \pm 0.27 \%$, and $8.0 \pm 0.84 \%$ ) (Fig. 2) in a dose-dependent manner. There was a significant difference between the amplitude of group (4 $\mathrm{min}$ ) and the corresponding negative control $(\mathrm{P}<0.05)$. This difference was more significant at prolonged incubation time $(\mathrm{P}<0.001)$.

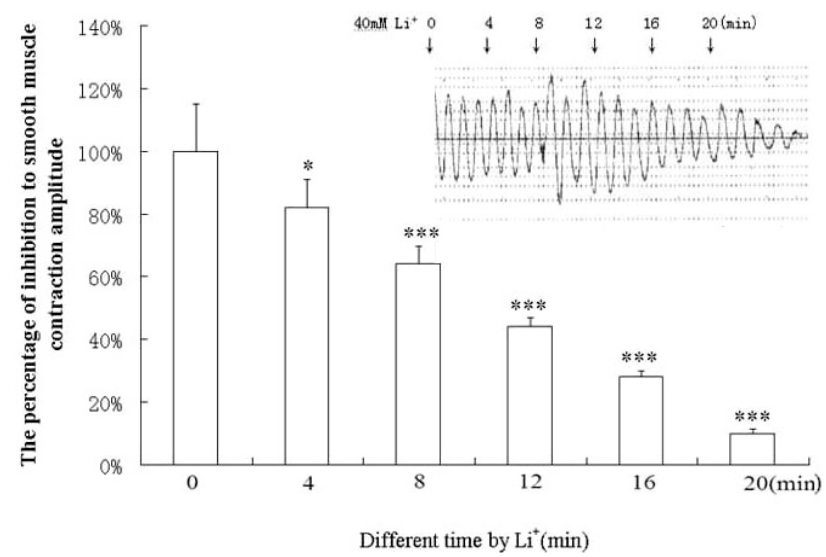

Fig. 2. Effect of lithium on the amplitude of smooth muscle contraction at different incubation time. The inset represents the diagram of scope and frequency curves of smooth muscle contraction. The arrows show that the contraction scope and frequency were changed under the $20 \mathrm{mM}$ lithium concentration at different incubation times. Asterisks indicate significant differences between particular incubation time groups $(* * * \mathrm{P}<0.001, * \mathrm{P}<0.05)$. Data are means \pm S.D. $(\mathrm{n}=8)$.

Effect of different lithium concentrations on $M L C_{20}$ phosphorylation by MLCK

The high sensitivity and efficacy of $\mathrm{MLC}_{20}$ phosphorylation by MLCK in the presence of $\mathrm{Ca}^{2+}, \mathrm{CaM}$ and low concentration of MLCK is well known (Tansey et al. 1994). Thus myosin ( $1 \mu \mathrm{M})$ could be phosphorylated with at least $0.005 \mu \mathrm{M}$ MLCK. We have therefore chosen $2 \mu \mathrm{M}$ MLCK and $4 \mu \mathrm{M}$ myosin concentrations for $\mathrm{MLC}_{20}$ phosphorylation. The lanes 0-4 (Fig. 3), which depict negative control (without MLCK and lithium), positive control (without lithium) as well as 5, 10 and $20 \mathrm{mM}$ lithium, indicate $0 \%, 100 \pm 9.91 \%, 87 \pm 0.85 \%$, $50 \pm 0.53 \%$, and $34 \pm 0.36 \%$ of $\mathrm{MLC}_{20}$ phosphorylation. The extent of phosphorylation in lanes 2, 3 and 4 was decreasing with increased lithium concentration in a dose-dependent manner. There was a significant difference between the amplitude of group $(5 \mathrm{mM})$ and the corresponding positive control $(0 \mathrm{mM})(\mathrm{P}<0.05)$. This difference became more significant at higher lithium concentrations $(\mathrm{P}<0.001)$.

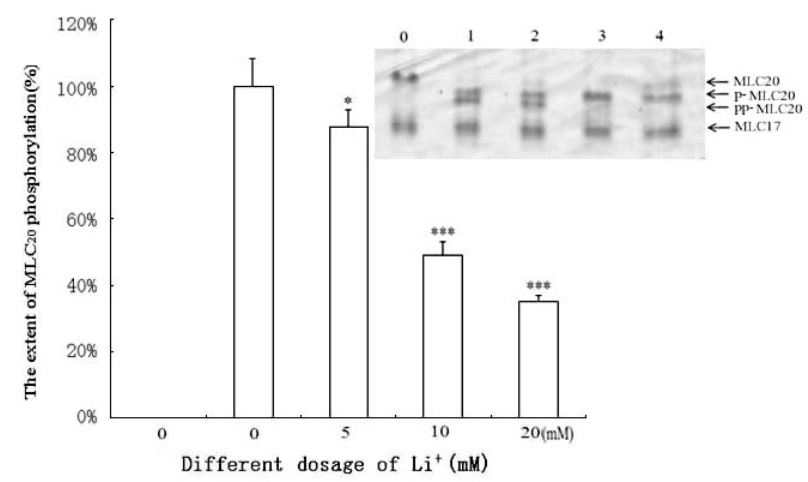

Fig. 3. Effect of lithium on $M L C_{20}$ phosphorylation by MLCK at different lithium concentrations. The lanes $0-4$ show the negative control (blank control without incubation), positive control (without lithium), 5, 10, $20 \mathrm{mM}$ lithium concentration group in the same incubation time. $4 \mu \mathrm{M}$ myosin $\left(1.76 \mathrm{mg}^{\prime} \mathrm{ml}^{-1}\right)$ were used at $25{ }^{\circ} \mathrm{C}$ for $20 \mathrm{~min}$ in the incubation. Gizzard smooth muscle myosin, the 20,000 $\mathrm{Mr}$ light chain $\left(\mathrm{L}_{20}\right)$ of which is phosphorylated in vitro with a calmodulin-myosin light chain kinase system. It is separated into 5 isolated bands on a Glycerol-PAGE. Their mobilities were in the following order: myosin with unphosphorylated $\mathrm{L}_{20}\left(\mathrm{~L}_{20}\right)<$ monophosphorylated $\mathrm{L}_{20}$ $\left(p-L_{20}\right)<$ myosin with diphosphorylated $L_{20}\left(p p-L_{20}\right)<$ myosin with unphosphorylated $\mathrm{L}_{17} \quad\left(\mathrm{~L}_{17}\right) . \quad \mathrm{MLC}_{20}$ represents unphosphorylated $20 \mathrm{KDa}$ myosin light chain; $\mathrm{p}-\mathrm{MLC}_{20}$ represents monophosphorylated $20 \mathrm{KDa}$ myosin light chain; pp-MLC $\mathrm{C}_{20}$ represents diphosphorylated $20 \mathrm{KDa}$ myosin regulatory light chains; $\mathrm{MLC}_{17}$ represents $17 \mathrm{KDa}$ myosin essential light chains. The abscissa was different lithium concentration; the ordinate was the relative extent of $M L C_{20}$ phosphorylation (*** $\mathrm{P}<0.001$, or $* \mathrm{P}<0.05)$. Data are means \pm S.D. $(n=8)$.

Effect of lithium on $M L C_{20}$ phosphorylation by $M L C K$ at different incubation times

Furthermore, we investigated $\mathrm{MLC}_{20}$ phosphorylation by MLCK in the presence of $20 \mathrm{mM}$ lithium for three different incubation times, i.e. 5, 10 and $20 \mathrm{~min}$. The lanes 0-4 (Fig. 4) show $0 \%, 97 \pm 0.99 \%, 81 \pm 0.87 \%$, $50 \pm 5.4 \%, 27 \pm 2.9 \%$ of $\mathrm{MLC}_{20}$ phosphorylation. The extent of $\mathrm{MLC}_{20}$ phosphorylation in lanes 2, 3 and 4 was decreasing with increasing incubation time in a timedependent manner. There was a significant difference between the amplitude of group ( $5 \mathrm{~min}$ ) and the corresponding positive control $(\mathrm{P}<0.05)$ and these 


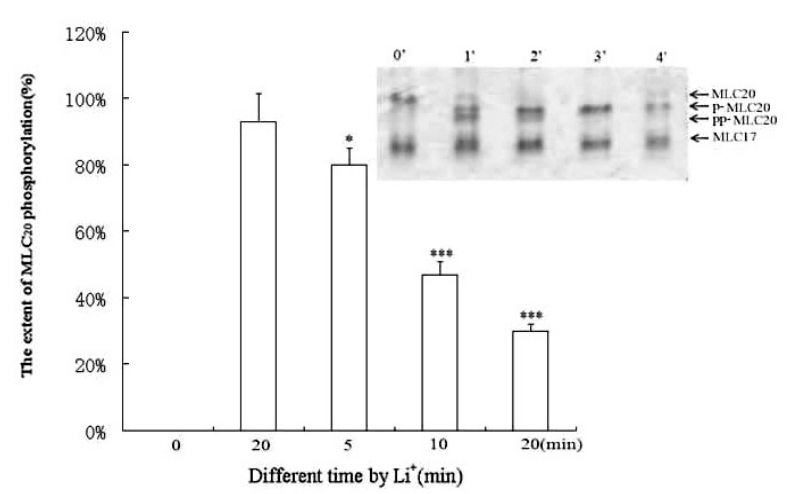

Fig. 4. Effect of lithium on $M L C_{20}$ phosphorylation by MLCK at different incubation times. The lanes $0-4$ show the negative control (blank control without incubation), positive control (without lithium), 5, 10, 20 min incubation time group in the $20 \mathrm{mM}$ lithium concentration, respectively. Incubation times for lane $0^{\prime}=0 \mathrm{~min}$, lane $1^{\prime}=20 \mathrm{~min}$ (without lithium), lane $2^{\prime}=$ $5 \mathrm{~min}$ (with $20 \mathrm{mM}$ lithium), lane $3^{\prime}=10 \mathrm{~min}$ (with $20 \mathrm{mM}$ lithium), lane $4^{\prime}=20 \mathrm{~min}$ (with $20 \mathrm{mM}$ lithium) were chosen. $4 \mu \mathrm{M}$ myosin $\left(1.76 \mathrm{mg}^{\prime} \mathrm{ml}^{-1}\right)$ were used at $25{ }^{\circ} \mathrm{C}$. MLC 20 represents unphosphorylated $20 \mathrm{KDa}$ myosin light chain; $\mathrm{p}-\mathrm{MLC}_{20}$ represents monophosphorylated $20 \mathrm{KDa}$ myosin light chain; pp- $\mathrm{MLC}_{20}$ represents diphosphorylated $20 \mathrm{KDa}$ myosin regulatory light chains; $\mathrm{MLC}_{17}$ represents $17 \mathrm{KDa}$ myosin essential light chains. Significant differences: $* * * \mathrm{P}<0.001, * \mathrm{P}<0.05$ compared to the corresponding controls. Data are means \pm S.D. $(n=8)$.

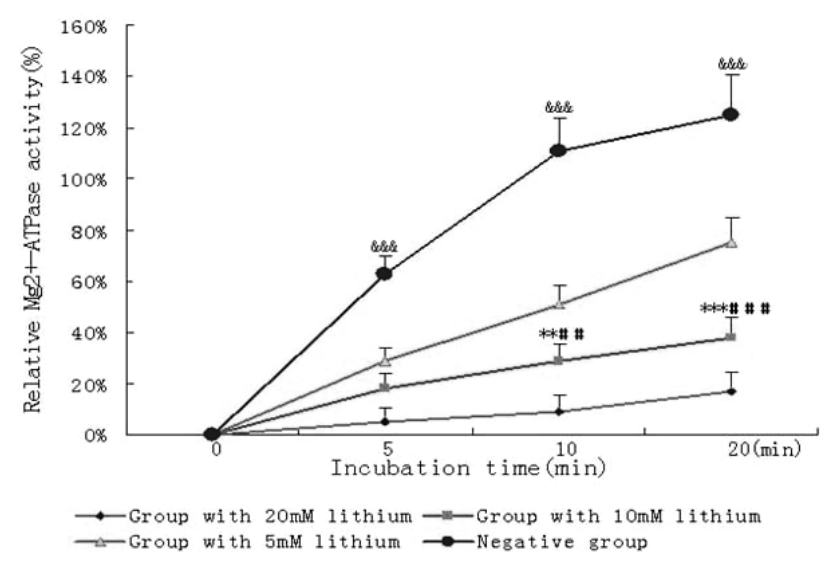

Fig. 5. Effect of different lithium concentrations on myosin $\mathrm{Mg}^{2+}$-ATPase activities at different incubation times. The curve $\bullet, \mathbf{\|} \boldsymbol{\Delta}$ and $\bullet$ represents the $\mathrm{Mg}^{2+}$-ATPase activities in groups with $20 \mathrm{mM}, 10 \mathrm{mM}, 5 \mathrm{mM}$ lithium and negative group respectively. $4 \mu \mathrm{M}$ myosin and $2 \mu \mathrm{M}$ MLCK were used in the assay for different incubation times, i.e., 5, 10, $20 \mathrm{~min}$. Significant differences: \&\&\& $\mathrm{P}<0.001$ compared with other groups with $5,10,20 \mathrm{mM}$ lithium; $* * P<0.01$ compared. Data are means \pm S.D. $(n=8)$.

differences became more significant at increasing incubation time $(\mathrm{P}<0.001)$.

Effect of different lithium concentration on myosin $\mathrm{Mg}^{2+}$-ATPase activities at different incubation times

Figure 5 shows that myosin $\mathrm{Mg}^{2+}$-ATPase activities measured at three lithium concentrations were all enhanced with prolonging of the incubation time. Our results indicated that at all incubation times, the highest $\mathrm{Mg}^{2+}$-ATPase activity was observed when myosin was studied in the negative group, and the enzyme activity decreased progressively with increasing lithium concentration. The differences between $\mathrm{Mg}^{2+}$-ATPase activities in different groups become more obvious with the extension of incubation time. There were significant differences between each lithium group and negative group $(\mathrm{P}<0.001)$ and between incubations for 10 and $20 \min (\mathrm{P}<0.01)$.

\section{Discussion}

Our results (Figs 1 and 2) indicated that lithium (10-40 mM) could inhibit the contraction in duodenum in a dose-related and time-dependent manner. It is most likely caused by the inhibition of myosin phosphorylation and $\mathrm{Mg}^{2+}$-ATPase activity (Figs 3-5).

There are controversies on the pharmacological actions of lithium and their mechanisms. People general thought that lithium enhances locomotor activity induced by DOI and Fos-like immunoreactivity (Moorman and Leslie 1998). On the other hand, lithium can downregulate $\mathrm{PKB} / \mathrm{Akt}$ and cyclin $\mathrm{E}$ in hepatocellular carcinoma cells (Erdal et al. 2005). Lithium also regulates PKC-mediated intracellular cross-talk and gene expression in the CNS in vivo (Chen et al. 2000) and inactivates $\mathrm{Gi}$ modulation of adenylate cyclase in brain (Monica et al. 1992). Though lithium could inhibit glycogen synthase kinase-3, it could not pose a higher risk for the development of cancers of the Wnt pathway (Gould et al. 2003). In addition, lithium regulates the proliferation of stem-like cells in retinoblastoma cell lines possibly through the canonical Wnt signaling pathway (Silva et al. 2010). It has also been observed that lithium carbonate can interact with L-tryptophan (Song Le et al. 2009).

However, there are also different opinions on the mechanism of gastrointestinal response. It was reported that lithium (45 mM) inhibits the $\mathrm{Na}^{+} / \mathrm{Ca}^{2+}$ exchanger (Kupriyanov et al. 1997) and activates mammalian $\mathrm{Na}^{+} / \mathrm{H}^{+}$exchanger in muscle (Kobayashi et al. 2000). Thus it can diminish $\mathrm{Ca}^{2+}$ entry through $\mathrm{Na}^{+}-\mathrm{Ca}^{2+}$ exchanger. Moreover, lithium decreases all mechanical and energetic properties of paired-pulse contractions (Savio-Galimberti and Ponce-Hornos 2006). However, other investigators believe that lithium (45 mM) decreases pressure developed and pressure-time integral, 
respectively. Lithium possibly acts on an additional myocardial $\mathrm{Ca}^{2+}$ sensitive locus (different from the $\mathrm{Na}^{+}$$\mathrm{Ca}^{2+}$ exchanger) (Bonazzola et al. 2002). However, lithium in a high concentration decreases significantly $\mathrm{Ca}^{2+}$ mobilization only in the presence of ML-9. These results suggest that the mechanism of lithium action may include a compensatory effect on MLCK modulation (Suzuki et al. 2004).

We used Glycerol-PAGE to analyze the phosphorylated state of gizzard smooth muscle. Thus we could evaluate the activity of MLCK by observing the mono- or di-phosphorylated myosin on Glycerol-PAGE (Takano-Ohmuro and Kohama 1986, Tang et al. 2005). It is known that phosphorylation of myosin regulatory light chain (RLC) at Ser19 (monophosphorylation) promotes filament assembly and enhances actin-activated ATPase activity, while phosphorylation at both Ser19 and Thr18 (diphosphorylation) further enhances the ATPase activity (Uehara et al. 2008). Our results confirmed that lithium (10-45 mM) inhibited the contraction of intestinal muscle in a dose-related manner and in a time dependent manner. Similarly, lithium also inhibits the extent of myosin phosphorylation in a dose-related and time-dependent manner.

Our experiments indicated that the results about phosphorylation of $\mathrm{MLC}_{20}$ were paralleled with those about $\mathrm{Mg}^{2+}$-ATPase activity. Lithium also inhibited the extent of $\mathrm{Mg}^{2+}$-ATPase activity in a dose-related manner. Nevertheless, the $\mathrm{Mg}^{2+}$-ATPase can catalyses the hydrolysis of myosin ATP in the presence of actin or calcium ions to form myosin ADP and orthophosphate. This reaction is the immediate source of free energy that drives muscle contraction. Hydrolysis of ATP by myosin is directly related to contractile function and structural changes in the head region of myosin during a contraction (Thomas et al. 1995). It is likely that the changes in myosin enzymatic activity accompany the changes in myosin structure and function. For this reason, the lower was $\mathrm{Mg}^{2+}$-ATPase activity, the lower muscle contraction force was developed.

Our results could explain the molecular mechanism of gastrointestinal side effects, i.e. the effect of lithium on the $\mathrm{MLC}_{20}$ phosphorylation by MLCK. Lithium inhibited smooth muscle contraction through the inhibition of myosin phosphorylation and $\mathrm{Mg}^{2+}$-ATPase activity. In the future we shall study how lithium interacts with the effective region of MLCK.

\section{Conflict of Interest}

There is no conflict of interest.

\section{Acknowledgements}

We thank Professor Norma Adragna, Professor Kazuhiro Kohama, Professor Lin Mao-Zhang and Professor Wang Li-Wen, and Professor Jiang Xin, for their valuable comments. This work was supported by the grants of National Natural Science Foundation of China (No. 30772601).

\section{References}

ABDEL-ZAHER AO: The myoneural effects of lithium chloride on the nerve-muscle preparations of rats. Role of adenosine triphosphate-sensitive potassium channels. Pharmacol Res 41: 163-178, 2000.

ADIPUDI V, REDDY VK: Effect of chronic lithium chloride on membrane adenosine triphosphatases in certain postural muscles of rats. Eur J Pharmacol 23: 7-13, 1994.

ANDERSON R, WALTERS L, GRABOW G, VAN DER MERWE M, VAN RENBURG CE: The effects of lithium on the functions of human neutrophils and lymphocytes in vitro and in vivo. S Afr Med J 2: 519-523, 1982.

BONAZZOLA P, EGIDO P, MARENGO FD, SAVIO-GALIMBERTI E, PONCE-HORNOS JE: Lithium and KB-R7943 effects on mechanics and energetics of rat heart muscle. Acta Physiol Scand 176: 1-11, 2002.

BRADFORD MM: A rapid and sensitive method for the quantitation of microgram quantities of protein utilizing the principle of protein-dye binding. Anal Biochem 7: 248-254, 1976.

CHEN G, MASANA MI, MANJI HK: Lithium regulated PKC-mediated intracellular cross-talk and gene expression in the CNS in vivo. Bipolar Disord 2: 217-236, 2000.

DEHPOUR AR, GHAFOURIFAR P, SAMENIAN J, SADEGHIPOUR HR, SADR SS: The effect of lithium on endothelial-dependent relaxation in rat isolated aorta. Gen Pharmacol 26: 1003-1007, 1995.

DEHPOUR AR, SAMINI M, GHAFOURIFAR P, KYANI H: Inhibition by lithium of neomycin-induced release of N-acetyl-beta-glucosaminidase in the rat heart. Pharmacol Toxicol 76: 202-205, 1995. 
DIEKMANN U: Comment on NIETHAMMER R, KELLER A, WEISBROD M: Delirium syndrome as lithium sideeffect with normal lithium levels. Psychiatr Prax 27: 417, 2000.

ERDAL E, OZTURK N, CAGATAY T, EKSIOGLU-DEMIRALP E, OZTURK M: Lithium-mediated downregulation of $\mathrm{PKB} / \mathrm{Akt}$ and cyclin $\mathrm{E}$ with growth inhibition in hepatocellular carcinoma cells. Int J Cancer 115: 903-910, 2005.

GILL J, SINGH H, NUGENT K: Acute lithium intoxication and neuroleptic malignant syndrome. Pharmacotherapy 23: 811-815, 2003.

GOULD TD, GRAY NA, MANJI HK: Effects of a glycogen synthase kinase-3 inhibitor, lithium, in adenomatous polyposis coli mutant mice. Pharmacol Res 48: 49-53, 2003.

HU M, WU Y, WU H: Influence of streptozotocin-induced diabetes in rats on the lithium content of tissue and the effect of dietary lithium supplements on this diabetic condition. Metabolism 48: 558-563, 1999.

IDE N, GOTOU S, MORI M: Hospital pharmacists prevented advance of lithium intoxication through pharmaceutical interventions. Yakugaku Zasshi 129: 1007-1011, 2009.

KASHOUR T, BURTON T, DIBROV A, AMARA F: Myogenic signaling by lithium in cardiomyoblasts is Akt independent but requires activation of the beta-catenin-Tcf/Lef pathway. J Mol Cell Cardiol 35: 937-951, 2003.

KIELCZYKOWSKA M, PASTERNAK K, MUSIK I: The influence of lithium on calcium and magnesium homeostasis in serum and tissues of rats. Ann Univ Mariae Curie Sklodowska Med 58: 281-284, 2003.

KOBAYASHI Y, PANG T, IWAMOTO T, WAKABAYASHI S, SHIGEKAWA M: Lithium activates mammalian $\mathrm{Na}^{+} / \mathrm{H}^{+}$exchangers: isoform specificity and inhibition by genistein. Pflügers Arch 439: 455-462, 2000.

KOZMA C: Neonatal toxicity and transient neurodevelopmental deficits following prenatal exposure to lithium: Another clinical report and a review of the literature. Am J Med Genet A 132: 441-444, 2005.

KUPRIYANOV VV, XIANG B, YANG L, DESLAURIERS R: Lithium ion as a probe of $\mathrm{Na}^{+}$channel activity in isolated rat hearts: a multinuclear NMR study. NMR Biomed 10: 271-276, 1997.

MASANA MI, BITRAN JA, HSIAO JK, POTTER WZ: In vivo evidence that lithium inactivates Gi modulation of adenylate cyclase in brain. $J$ Neurochem 59: 200-205, 1992.

MOORMAN JM, LESLIE RA: Paradoxical effects of lithium on serotonergic receptor function: an immunocytochemical, behavioural and autoradiographic study. Neuropharmacology 37: 357-374, 1998.

OZTURK Y, YILDIZOGLU-ARI N, ALTAN N, ALTAN VM: Effect of lithium on gastrointestinal complications in alloxan-diabetic rats. Gen Pharmacol 23: 769-773, 1992.

RAVICHANDRAN D, COOPER A, JOHNSON CD: Growth inhibitory effect of lithium gamma-linolenate on pancreatic cancer cell lines: the influence of albumin and iron. Eur J Cancer 34: 188-192, 1998.

SADOUL JL, KEZACHIAN B, FREYCHET P: Lithium therapy and hyperthyroidism: disease caused or facilitated by lithium? Review of the literature apropos of a case of hyperthyroidism preceded by transient hypothyroidism. Ann Endocrinol (Paris) 54: 353-358, 1994.

SAVIO-GALIMBERTI E, PONCE-HORNOS JE: Effects of caffeine, verapamil, lithium, and KB-R7943 on mechanics and energetics of rat myocardial bigeminies. Am J Physiol 290: H613-H623, 2006.

SCHÜMANN K, HUNDER G: A modified device for the differentiated study of intestinal transfer in isolated segments from mice and suckling rats in vitro. $J$ Pharmacol Toxicol Methods 36: 211-217, 1996.

SILVA AK, YI H, HAYES SH, SEIGEL GM, HACKAM AS: Lithium chloride regulates the proliferation of stem-like cells in retinoblastoma cell lines: a potential role for the canonical Wnt signaling pathway. Mol Vis 13: 36-45, 2010.

SONG LE X, BAI L: Old drugs, new tricks: the effect of molecule-ion interactions on the precipitation-dissolution equilibrium of lithium carbonate in aqueous solution and on the chiral recognition of cyclodextrins to D-, L-tryptophan. J Phys Chem B 113: 11724-11731, 2009.

SUZUKI K, KUSUMI I, AKIMOTO T, SASAKI Y, KOYAMA T: Effects of lithium and valproate on agonist-induced platelet intracellular calcium mobilization: relevance to myosin light chain kinase. Prog Neuropsychopharmacol Biol Psychiatry 28: 67-72, 2004. 
TAKANO-OHMURO H, KOHAMA K: Analysis of smooth muscle myosin phosphorylation with native pyrophosphate gels and its application to studies on myosin phosphorylation in contracting smooth muscle. $J$ Biochem 100: 1681-1684, 1986.

TANG Z, CHEN H, YANG J, DAI S, LIN Y: The comparison of $\mathrm{Ca}^{2+} / \mathrm{CaM}$-independent and $\mathrm{Ca}^{2+} / \mathrm{CaM}$-dependent phosphorylation of myosin light chains by MLCK. Physiol Res 54: 671-678, 2005.

TANSEY MG, LUBY-PHELPS K, KAMM KE, STULL JT: $\mathrm{Ca}^{2+}$-dependent phosphorylation of myosin light chain kinase decreases the $\mathrm{Ca}^{2+}$ sensitivity of light chain phosphorylation within smooth muscle cells. J Biol Chem 269: 9912-9920, 1994.

THOMAS DD, RAMACHANDRAN S, ROOPNARINE O, HAYDEN DW, OSTAP EM: The mechanism of force generation in myosin: a disorder-to-order transition, coupled to internal structural changes. Biophys $J \mathbf{6 8}$ : 135S-141S, 1995.

UEHARA R, HOSOYA H, MABUCHI I: In vivo phosphorylation of regulatory light chain of myosin II in sea urchin eggs and its role in controlling myosin localization and function during cytokinesis. Cell Motility Cytoskeleton 65: 100-115, 2008.

VINCENT MB: Lithium inhibits substance $\mathrm{P}$ and vasoactive intestinal peptide-induced relaxations on isolated porcine ophthalmic artery. Headache 32: 335-339, 1992.

YAN XB, HOU HL, WU LM: Lithium regulates hippocampal neurogenesis by ERK pathway and facilitates recovery of spatial learning and memory in rats after transient global cerebral ischemia. Neuropharmacology 53: 487495, 2007. 